\title{
Endobronchial Malignant Fibrous Histiocytoma: Case Report of an Unusual Presentation and Palliative Flexible Bronchoscopic Resection
}

\author{
Jung-Hyun Kim MD, Sang-Ho Cho MD PhD, Eun-Kyung Kim MD, \\ Ji-Hyun Lee MD PhD, and Hye-Cheol Jeong MD PhD
}

\begin{abstract}
Primary malignant fibrous histiocytoma (MFH) of the lung is a very rare neoplasm that usually presents as a parenchymal mass. Here we report an unusual case of primary MFH of the bronchus, showing relatively benign clinical features. We performed a palliative resection via flexible bronchoscopy, using a polypectomy snare. The patient has survived for over 2 years after being diagnosed with an endobronchial mass, later found to be MFH, and 14 months post-debulking. There is a possibility that endobronchial MFH has a more favorable prognosis than MFH of other origins. If this is true, interventional bronchoscopy can be a reasonable option for non-operable cases of MFH. Key words: malignant fibrous histiocytoma; bronchoscopy; palliative care; airway obstruction. [Respir Care 2013;58(8):e92-e94. (C) 2013 Daedalus Enterprises]
\end{abstract}

\section{Introduction}

Primary malignant fibrous histiocytoma (MFH) of the lung is a very rare neoplasm. ${ }^{1}$ A previous study reported 13 cases of primary MFH of the lung. ${ }^{2}$ In that case series the median age of patients was 54 years, and the median survival was 16 months (range 6-36 months). This type of neoplasm is usually resistant to chemotherapy or radiotherapy, as is the case with other sarcomas, and has high local recurrence rate and metastasis rate. ${ }^{1-4}$ Recently, we experienced an unusual case of MFH, which presented as an endobronchial mass with no parenchymal lesion or distant metastasis. Because the patient was not suitable for surgical resection, we performed a palliative resection of the mass by flexible bronchoscopy, using a polypectomy snare.

\footnotetext{
The authors are affiliated with the Division of Pulmonary and Critical Care Medicine, Department of Internal Medicine and Department of Pathology, ${ }^{1}$ CHA Bundang Medical Center, College of Medicine, CHA University, Seongnam, South Korea

Correspondence: Hye-Cheol Jeong MD, Division of Pulmonology and Critical Care Medicine, Department of Internal Medicine, CHA Bundang Medical Center, 59 Yatap-Ro, Seongnam Gyunggido 463-712, South Korea. E-mail: jhcmd@hanmail.net.
}

DOI: $10.4187 /$ respcare.01996

\section{Case Summary}

A 61-year-old man presented to our clinic for shortness of breath and chest discomfort. Six months before presentation, he was diagnosed with stage 4 lung cancer at a different clinic, due to an endobronchial mass and pleural effusion shown on his computed tomography (CT) scan. However, neither bronchoscopy nor diagnostic thoracentesis was performed. He had received only symptomatic treatment, including pain control, medications for cough and sputum, and supplemental oxygen. A medical interview revealed a history of schizophrenia for 10 years, but he was not on medications. He was a 40-pack-year smoker and a serious alcohol abuser.

Physical examination revealed decreased breath sounds on the right lower lung field, and pretibial pitting edema. Chest $\mathrm{x}$-ray showed atelectasis of the right lower lobe, with pleural effusion. A CT scan revealed a mass in the bronchus intermedius, pleural effusion, and pulmonary thromboembolism (Fig. 1). Echocardiography showed dilated cardiomyopathy, with a $17 \%$ ejection fraction and an intracardiac thrombus. He refused further evaluation for the endobronchial mass and pleural effusion. Clinical diagnoses of lung cancer and alcoholic cardiomyopathy were made. A cardiologist prescribed diuretics, an angiotensin converting enzyme inhibitor, digitalis, and warfarin for his heart problems. Three months later, a follow-up chest radiograph showed decreased pleural effusion. Bronchoscopy was performed, and a polypoid mass was found 
Initial
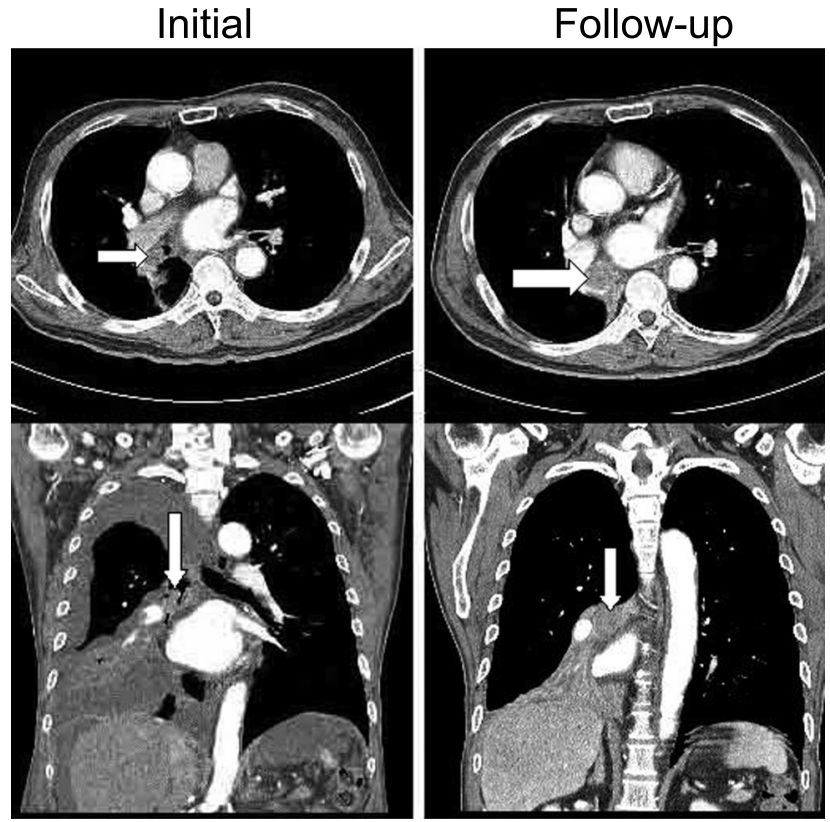

Fig. 1. Initial computed tomogram shows an endobronchial mass (arrow) in the right bronchus intermedius. Follow-up computed tomogram shows a bronchial mass obstruction (arrow) and obstructive pneumonitis.

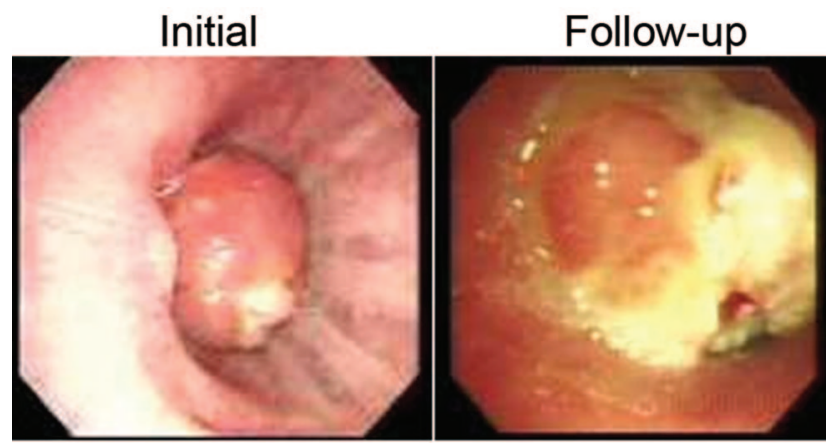

Fig. 2. Initial bronchoscopy shows an endobronchial mass. The scope successfully traversed the lesion. Follow-up bronchoscopy 2 years later shows complete lumen obstruction by the mass.

in the bronchus intermedius (Fig. 2). The pathology report for the bronchoscopic biopsy was non-specific granulation. A diagnostic thoracentesis revealed transudate fluid, without malignant cells. We therefore felt that he may have been misdiagnosed with lung cancer, so considered surgical resection of the endobronchial mass. However, we decided to observe the mass without surgical resection, because substantial operative risk was estimated.

Two years later the sputum became more purulent and his dyspnea worsened. Chest x-ray showed an obstructive collapse of the lower lobe of the right lung. A follow-up CT scan showed complete resorption of the previously noticed thromboembolism. However, the mass completely

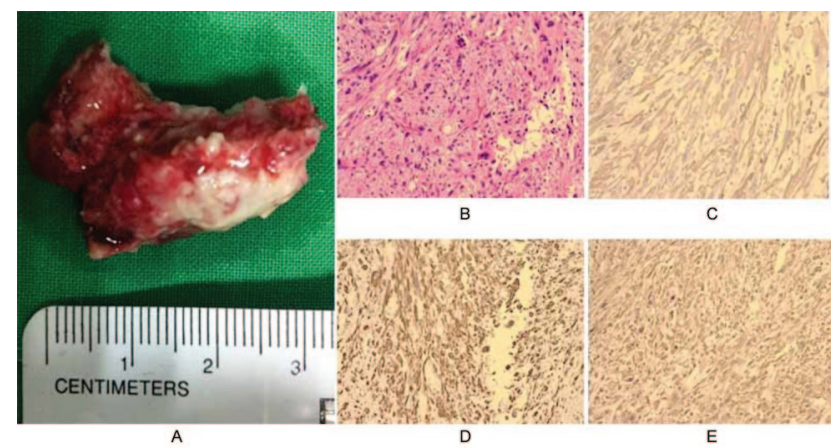

Fig. 3. A: Endobronchial mass. B: Storiform pattern with bizarre anaplastic tumor cells arranged haphazardly in sheets (hematoxylin and eosin stain). Immunohistostain was positive for smoothmuscle actin $(C)$, vimentin (D), and CD68 (E), but negative for desmin and cytokeratin.

obstructed the bronchial lumen at the level of the bronchus intermedius (see Fig. 1).

We performed another bronchoscopy and found that a mass obstructed the lumen of the bronchus intermedius (Fig. 2). Curative operation was not an option because of his cardiac problems, so we introduced a gastrointestinal polypectomy snare into the channel of the flexible bronchoscope and performed a palliative partial mass resection. During the procedure a mild sedation was achieved using midazolam. The procedure was done without any complications. After the procedure the right lower lobe bronchus was patent, with only a small stalk of the tumor remaining. The pathology specimen consisted of a polypoid mass measuring $3.0 \times 1.5 \times 1.5 \mathrm{~cm}$. On multiple sections, the mass occupied most of the specimen and revealed multinodular gray white cut surfaces with focal necrosis. Microscopically it showed a storiform pattern with bizarre anaplastic tumor cells arranged haphazardly in sheets (Fig. 3). An extreme degree of pleomorphism and occasional multinucleation were noted. There was a focus of necrosis on the surface. The resection margin was free of the malignant tumor. Immunohistochemical stain revealed positive smooth-muscle actin, vimentin, and CD68. Desmin and cytokeratin were negative. The diagnosis was storiform-pleomorphic MFH. A fludeoxyglucose positron emission tomography scan revealed no evidence of distant metastasis. The mediastinal lymph nodes were not changed in size, compared to previous CT scan, and did not show notable fluorodeoxyglucose uptake.

After the pathology diagnosis we recommended repeat bronchoscopy with electrocautery of the remnant lesion, but the patient refused any further treatment. He was followed clinically and radiographically. Ten months after resection, follow-up CT scan revealed regrowth of the mass and bronchial obstruction, but he refused further treatment. Fourteen months after the resection he was still alive and minimally symptomatic. 


\section{Discussion}

Most cases of primary MFH of the lung present as a peripheral lung mass. ${ }^{1-3}$ Although a study reported that $33 \%$ of patients who received combination chemotherapy showed partial response, MFH is usually resistant to chemotherapy or radiotherapy. ${ }^{3,5}$ A previous study revealed a 5 -year survival rate of 58\% and a 10-year survival rate of $38 \% .6$ Surgical resection is the best treatment option when the disease is limited. ${ }^{5,7} \mathrm{~A}$ few cases of MFH arising from the pleura and diaphragm have shown aggressive clinical features. ${ }^{8,9}$ However, the bronchus and trachea are extremely rare sites for MFH, and to our knowledge, there are only 10 cases reported in the literature. ${ }^{1,10-17}$ Judging from these reports, it seems that endobronchial MFH shows relatively favorable clinical features, compared to $\mathrm{MFH}$ of other sites. Our patient has survived for more than 3 years without distant metastasis or parenchymal invasion, which is a very unusual presentation. Surgical resection is the treatment of choice whenever possible, but we performed a palliative resection using flexible bronchoscopy, because substantial operative risk was expected.

Currently, many novel treatment modalities, such as laser, argon plasma coagulation, electrocauterization, stent, and cryotherapy, are available for interventional bronchoscopy. ${ }^{18}$ All of these options are available for both rigid and flexible bronchoscopy.

A recent report presented 3 cases of endobronchial tumors treated by flexible bronchoscopy with a polypectomy snare followed by electrocauterization. ${ }^{19}$ They used the same technique as we did in the present case, but their cases were benign tumors. In another report, Vinod et al used external beam radiotherapy to achieve local control. ${ }^{15}$ Conforti et al used yttrium-aluminum-garnet laser for a case of benign histiocytoma. ${ }^{20}$ However, benign histiocytoma is a different disease entity from $\mathrm{MFH}$, in that benign histiocytoma shows rare mitosis and no cellular atypia in histology, and has very low local recurrence rate and metastasis rate. ${ }^{21,22}$ Argon plasma coagulation ${ }^{23}$ and cryotherapy ${ }^{24}$ were also used in other reports. Although we do not know which modality is the best for endobronchial MFH, interventional bronchoscopy can be a reasonable alternative choice when surgery is not an option.

Primary MFH of the lung is very rare, and $\mathrm{MFH}$ of the bronchus is extremely rare. In this case of MFH confined to the bronchus, the patient has survived more than 3 years without distant metastasis or parenchymal invasion. A palliative bronchoscopic resection using a polypectomy snare was performed successfully under mild sedation, and provided sufficient symptom control for 10 months.

\section{REFERENCES}

1. Yousem SA, Hochholzer L. Malignant fibrous histiocytoma of the lung. Cancer 1987;60(10):2532-2541.
2. Gal AA, Koss MN, McCarthy WF, Loehholzer L. Prognostic factors in pulmonary fibrohistiocytic lesions. Cancer 1994;73(7):1817-1824.

3. Leite C, Goodwin JW, Sinkovics JG, Baker LH, Benjamen R. Chemotherapy of malignant fibrous histiocytoma. Cancer 1977;40(5): 2010-2014.

4. Weiss SW, Enzinger FM. Malignant fibrous histiocytoma: an analysis of 200 cases. Cancer 1978;41(6):2250-2266.

5. Rzyman W, Jaskiewicz K, Murawski M, Sternau A, Marjanski T, Karmolinski A, Dziadziuszko R. Primary malignant fibrous histiocytoma of the lung. Thorac Cardiovasc Surg 2007;55(3):186-189.

6. Gibbs JF, Huang PP, Lee RJ, McGrath B, Brooks J, McKinley B, et al. Malignant fibrous histiocytoma: an institutional review. Cancer Invest 2001;19(1):23-27.

7. Aoe K, Hiraki A, Maeda T, Onoda T, Makihata K, Takao K, et al. Malignant fibrous histiocytoma of the lung. Anticancer Res 2003; 23(4):3469-3474.

8. Yang HY, Weaver LL, Foti PR. Primary malignant fibrous histiocytoma of the pleura. A case report. Acta Cytol 1983;27(6):683-687.

9. Shim JJ, Cho YS, Kim HS, Choi SS, Choi CW, Yoo JH, et al. A case of primary malignant fibrous histiocytoma of the diaphragm. Tuberc Respir Dis (Seoul) 2003;54(6):645-650. Article in Korean.

10. Randleman CD, Unger ER, Mansour KA. Malignant fibrous histiocytoma of the trachea. Ann Thorac Surg 1990;50(3):458-459.

11. Shijubo N, Sugaya F, Imada A, Kudoh K, Suzuki A, Nakata H, et al. Malignant fibrous histiocytoma presenting as an endobronchial polyp of the carina. Eur Respir J 1995;8(8):1430-1431.

12. Aribaş OK, Görmüş N. Obstructing endobronchial malignant fibrous histiocytoma. Eur J Cardiothorac Surg 2001;19(5):716-718.

13. Louie S, Cross CE, Amott TR, Cardiff R. Postirradiation malignant fibrous histiocytoma of the trachea. Am Rev Respir Dis 1987;135(3): 761-762.

14. Wang YH, Wang JL, Lin AS, Cheng L. Malignant fibrous histiocytoma of the trachea combined with thymic carcinoma: a case report. Changgeng Yi Xue Za Zhi 1993;16(4):271-274.

15. Vinod SK, Macleod CA, Barnes DJ, Fletcher J. Malignant fibrous histiocytoma of the trachea. Respirology 1999;4(3):271-274.

16. Grillo HC, Mathisen DJ. Primary tracheal tumors: treatment and results. Ann Thorac Surg 1990;49(1):69-77.

17. Sennaroğlu L, Sözeri B, Ataman M, Gököz O. Malignant fibrous histiocytoma of the trachea. Case report. Acta Otorhinolaryngol Belg 1996;50(2):147-149.

18. Bolliger CT, Sutedja TG, Strausz J, Freitag L. Therapeutic bronchoscopy with immediate effect: laser, electrocautery, argon plasma coagulation and stents. Eur Respir J 2006;27(6):1258-1271.

19. Rodrigues AJ, Coelho D, Dias Junior SA, Jacomelli M, Scordamaglio PR, Figueiredo VR. Minimally invasive bronchoscopic resection of benign tumors of the bronchi. J Bras Pneumol 2011;37(6):796-800.

20. Conforti S, Bonacina E, Ravini M, Torre M. A case of fibrous histiocytoma of the trachea in an infant treated by endobronchial ND:YAG laser. Lung Cancer 2007;57(1):112-114.

21. Giovani P, Patrikidou A, Ntomouchtsis A, Meditskou S, Thuau H, Vahtsevanos K. Benign fibrous histiocytoma of the buccal mucosa: case report and literature review. Case Report Med 2010;2010:306148. DOI: $10.1155 / 2010 / 306148$.

22. Menditti D, Laino L, Mezzogiorno A, Sava S, Bianchi A, Caruso G, et al. Oral benign fibrous histiocytoma: two case reports. Cases J 2009;2:9343.

23. Bugalho A, Oliveira A, Semedo J, Lourenço I, Carreiro L. Argonplasma treatment in benign metastasizing leiomyoma of the lung: a case report. Rev Port Pneumol 2010;16(6):921-923.

24. Schumann C, Hetzel M, Babiak AJ, Hetzel J, Merk T, Wibmer T, et al. Endobronchial tumor debulking with a flexible cryoprobe for immediate treatment of malignant stenosis. J Thorac Cardiovasc Surg 2010;139(4):997-1000. 